\title{
Atypical lipomas of the hand and forearm
}

\begin{abstract}
Three lipomas are presented: lipoma arborescens of the long flexor tendons, a forearm lipoma traversing the interosseous membrane and a thenar eminence lipoma with median nerve compression. Pre-operative magnetic resonance imaging defined the extent of lipomatous infiltration in each case. Excellent outcomes were observed after complete excision.
\end{abstract}

Keywords: lipoma, hand tumour, hand lipomas, lipoma arborescens, synovial lipomatosis
Volume 3 Issue I - 2015

\author{
Dallan P Dargan, Gareth J Price, Harry G \\ Lewis \\ Department of Plastic surgery, Ulster Hospital, Dundonald
}

Correspondence: Dallan P Dargan, Department of Hand and Reconstructive Microsurgery, National University Hospital Singapore, Tower Block Level I I, IE Kent Ridge Road, I 19228 , Singapore, Tel +65 8I892978, Email dallan_dargan@hotmail.com

Received: October 6, 20I5 | Published: October 24, 2015

\section{Introduction}

Lipomas which traverse compartments raise concerns of malignancy. Functional impairment may arise due to lesion bulk, nerve compression and tendon adherence. Lipoma arborescens involving the dorsal wrist and extensor tendons of the forearm and hand has been reported recently. ${ }^{1-3}$ The condition is extremely rare in this location and flexor tendon involvement contrasts with those in the recent literature.

\section{Case reports}

\section{Case I:Volar lipoma arborescens}

An 81year-old lady presented with gradually enlarging masses in the thenar area, first webspace dorsum and along the flexor tendons of the left hand. Global left hand pain which disturbed sleep was noted, with pincer grip weakness. The medical history included controlled hypothyroidism, hypertension and hypercholesterolaemia. MRI demonstrated a thenar eminence lesion (Figure 1), extending across the flexor tendons in the palm and forearm. Appearances were inconsistent with giant cell tumours or chronic synovitis. High fat content and gadolinium enhancement raised the possibility of liposarcoma. An ultrasound guided biopsy demonstrated benign adiposeand fibrous tissue. The hand was explored under general anaesthetic. Upon opening the carpal tunnel, multiple lipomatous lesions were present along the full extent of the flexor sheath (Figure 2). Each was excised with attached synovial tissue, similar to a rheumatoid synovectomy. A Y-shaped extension of the palmar incision, with division and ligation of the superficial palmar arch, provided access to deeper lesions. Synovial lipomatosis infiltrated the lumbricals and surrounded the flexor tendons. All branches of the median nerve were decompressed. Local anaesthetic was infiltrated and a double lumen Yates drain was placed. Histopathology confirmed benign adipose tissue with fibrovascularstroma and spindle cells. At one month, the wound had healed and finger flexion was full, with resolution of the neuropathy and no recurrence at eight months.

\section{Case 2: Forearm lipoma traversing interosseous membrane}

A 60year-old female secretary presented with swelling on the dorsal and volar aspects of her left non-dominant distal forearm and a mild ache at the base of the thumb. The lesion was non-tender and mobile, causing no functional impairment. Past medical history included hypercholesterolaemia, hypertension, gastroesophageal reflux and allergic rhinitis and easy bruising was reported. Ultrasound confirmed a well-defined, hyperechoic lesion, avascular on colour flow imaging, consistent with an intramuscular lipoma.MRI confirmed a $4 \times 2.5 \times 5.5 \mathrm{~cm}$ lobular fatty tumour of the distal forearm, bridging the anterior and posterior compartments (Figure 3), extending to the distal radioulnar joint, close to the interosseous nerve. Fine-needle aspiration cytology demonstrated benign spindle and epithelioid cells. The possibility of a benign fibrohystiocytic tumour, or lowgrade malignancy was raised and synovial sarcoma thought unlikely. Surgical exploration under was performed via a volar approach. A lipomatous lesion deep to the flexor tendons displaced the ulnar artery and nerve. The lesion penetrated the interosseous membrane, which required division for en masse excision. Histopathology reported a benignlipoma. A full functional recovery was noted, no recurrence at two years.

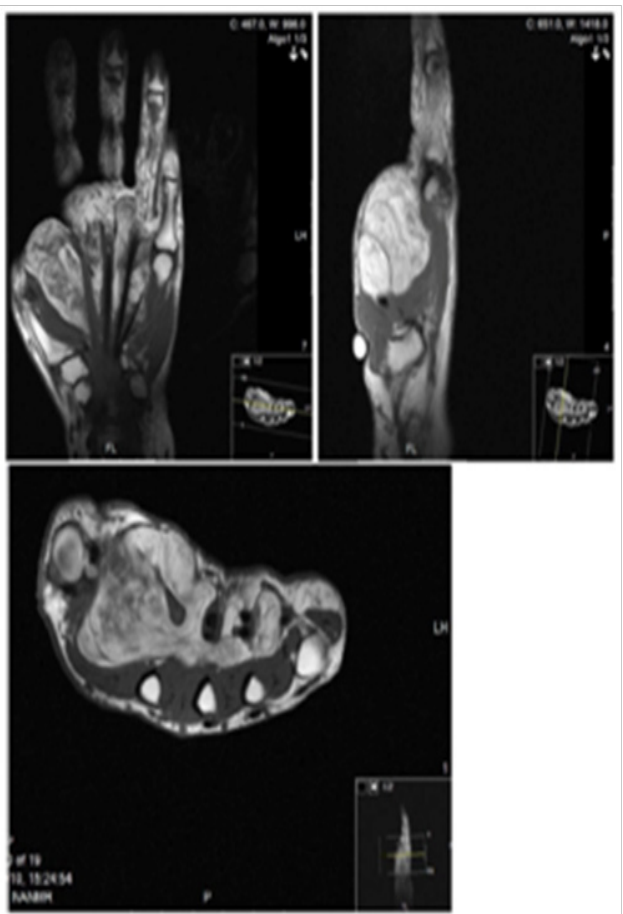

Figure I Coronal, sagittal and axial MR images of the left hand, showing lipomatous infiltration around the flexor tendons, and thenar mass. 


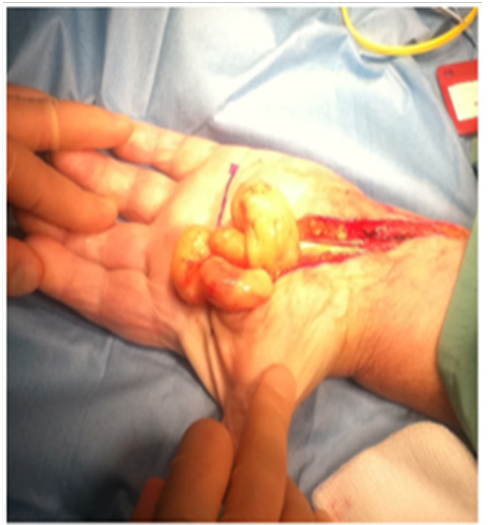

Figure 2 A volar approach extending across the wrist released a lobulated lipoma within the palm, which extended proximally along the flexor tendons.

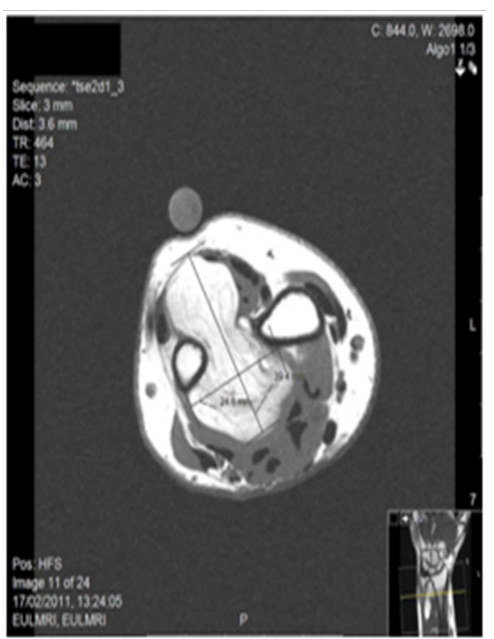

Figure 3 Axial TI MR Image of the left forearm demonstrating the mass of lipoma crossing the interosseous membrane between radius and ulna.

\section{Case 3: Thenar eminence lipoma with median nerve compression}

A 41year-old female classroom assistant with a history of hypertension, hypercholesterolaemia, cigarette smoking and BMI of 33.5 presented with an increasing swelling in her dominant right thenar eminence, compromising thumb movements. Bilateral carpal tunnel symptoms were present since pregnancy 2 years earlier. Radiographs confirmed no bony abnormality. MRI confirmed an intramuscular lipoma volar to the trapezium and trapezoid, at the radial border of the carpal tunnel, immediately radial to flexor pollicislongus. The lesion was well defined, with flat signal and fat suppression evident. There was little or no internal architecture, consistent with a lipoma. Surgical excision via a muscle splitting thenar incision was performed under general anaesthetic and tourniquet. A fourth ray incision was used for the carpal tunnel. Histopathological analysis confirmed a benign lipoma, of uniform consistency. The median nerve symptoms resolved, with no recurrence at four years.

\section{Discussion}

Lipomas occur rarely in the hand and fixation to an aponeurosis or confinement to a deep space may restrict mobility of the mass, with absence of the slip sign. Synovial lipomas of the hand may lie within a synovial sheath, or attached to the outer aspect ${ }^{4}$ and have been described in the palm, wrist and fingers. Lipomas of the midpalmar space may bulge through weak areas of the deep aponeurosis and track along lumbricals. ${ }^{4}$ Lipoma arborescens differs from lipoma simplex symmetricum due to the 'tree-like' pattern of lipomatosis infiltration and is a rare benign disorder.It can occur following scaphoid fracture ${ }^{3}$ and cause compression neuropathies. ${ }^{5}$ The expansive branching pattern allows clinical differentiation from angiofibrolipomas which may also involve dorsal wrist tendons. ${ }^{6}$ Differential diagnosis includes traumatic epithelial cysts, giant cell tumour, liposarcoma and hygroma of tendon sheath (tuberculous tenosynovitis). MRI identifies welldifferentiated liposarcoma with sensitivity and negative predictive value quoted as $100 \%$, but specificity of $83 \%$ and positive predictive value of $38 \%{ }^{7,8}$ Malignant transformation of lipomas is exceedingly rare and asymptomatic lipomas can be observed. Surgical dissection around neurovascular structures may be complex ${ }^{9}$ and recurrence has been noted with incomplete excision.

\section{Conclusion}

Atypical lipomas may cause symptoms and concern in this region and MRI and biopsy aid pre-operative planning. Excellent results are possible even in cases requiring complex dissection.

\section{Acknowledgements}

Thanks to Mr P Maginn, Consultant Orthopaedic Surgeon, Musgrave Park Hospital, Belfast and Mr A Brown, Consultant Plastic Surgeon, Ulster Hospital, Dundonald, Northern Ireland for two of the cases discussed.

\section{Conflict of interest}

The author declares no conflict of interest.

\section{References}

1. Stepan JG, Gelberman RH, Rubin DA, et al. Extra-articular lipoma arborescens of the dorsal aspect of the wrist with invasion of the extensor tendons a case report. JBJS Case Connect. 2013;3(1):e30.

2. Kamaci S, Ergen FB, Leblebicioglu G. Lipoma arborescens in the extensor tendon sheath of the hand secondary to foreign body reaction. $J$ Hand Surg Eur Vol. 2014;40(7):751-753.

3. Hill G, Phyo N. Extra-articular lipoma arborescens of the hand: an unusual case report. J Hand Surg Eur Vol. 2011;36(5): 422-423.

4. Straus FH. Deep lipomas of the hand. Ann Surg. 1931;94(2):269-273.

5. Leffert RD. Lipomas of the upper extremity. J Bone Joint Surg Br. 1972;54(6):1262-1266.

6. Kucuker I, Keles MK, Yosma E, et al. Angiofibrolipoma of the tendon sheath. Case Reports in Plastic Surgery and Hand Surgery. 2014;1(1):12 .

7. Gaskin CM, Helms CA. Lipomas, lipoma variants, and well-differentiated liposarcomas (atypical lipomas): results of MRI evaluations of 126 consecutive fatty masses. AJR Am J Roentgenol. 2004;182(3):733-739.

8. Babins DM, Lubahn JD. Palmar lipomas associated with compression of the median nerve. J Bone Joint Surg Am. 1994;76(9):1360-1362.

9. Nadar MM, Bartoli CR, Kasdan ML. Lipomas of the hand: a review and 13 patient case series. Eplasty. 2010;10:e66. 